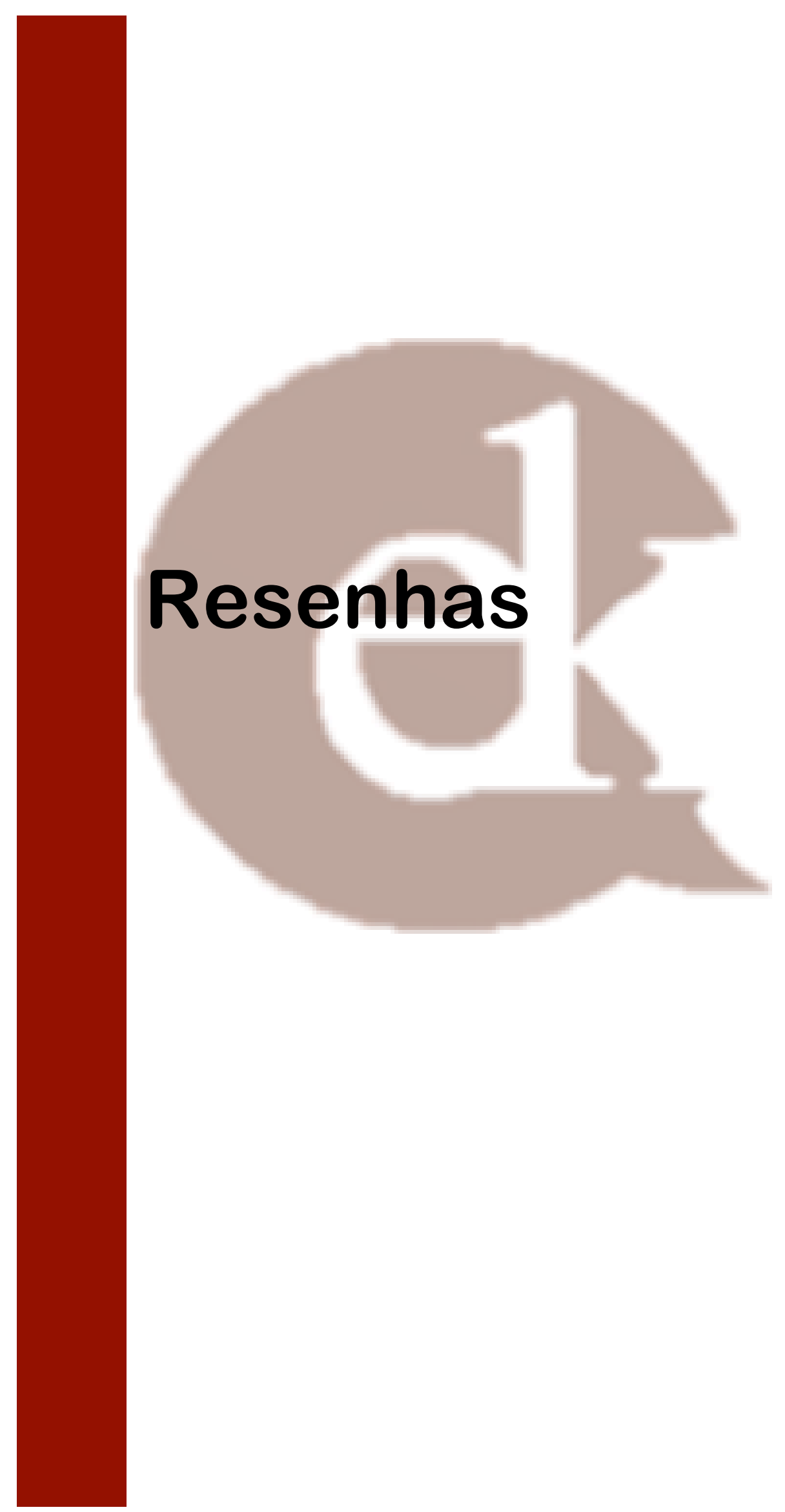




\section{O único e o singular}

DOI: 10.12957/ek.2020.48887

Dndo. Thiago Luiz de Sousa

thiago-luiz-sousa@hotmail.com

Universidade Federal de Minas Gerais (UFMG)

Paul Ricoeur (1913-2005) é um dos maiores filósofos do século XX. Certamente, o maior nome da hermenêutica na França. Sua obra é vasta, composta por quase 800 textos, que abordam diversas temáticas. Em sua fase mais madura, Ricoeur se arriscou em um novo gênero literário, as entrevistas, que posteriormente se tornaram livros e que hoje são de grande importância para a investigação de seu pensamento. Este gênero é tardio em sua obra, pois não conta com a precisão, delimitação e exaustiva revisão que sempre estão presentes em seus livros. Por outro lado, tais entrevistas, por não se prenderem à delimitação temática, permitem o enfrentamento de questões mais amplas, como o que é filosofia? Desse modo, a obra aqui resenhada, $O$ único e o singular, sem ser a única, pode ser considerada como uma importante chave de leitura para a obra ricoeuriana, em especial, para uma definição daquilo que Paul Ricoeur define como filosofia.

$O$ único e o singular é a transcrição de uma entrevista dada por Paul Ricoeur ao programa belga Noms de Dieux, de Edmond Blattchen, exibido ao final do ano de 1993. No entanto, tal livro, em sua edição francesa, só foi publicado no ano de 1999 e a brasileira, em 2002. O livro é dividido em cinco partes. Cada uma das partes é um bloco temático, nos quais o entrevistador propõe um tema para que, por sua vez, o filósofo francês apresente suas considerações. Os blocos temáticos são os seguintes: (1) Deus sem nome; (2) Um silêncio inquieto; (3) O poder e a fragilidade; (4) O filósofo, o poeta e o político; e (5) A primeira palavra jamais é a nossa. Apresentaremos, em seguida, um resumo sobre cada um deles. 


\section{(1) Deus sem nome}

Nesse bloco temático Ricoeur apresenta que Deus é sem nome por dois motivos principais: Ele é inominável e, ao mesmo tempo, apresenta uma multiplicidade de nomes. Dessa forma, o correto, segundo Ricoeur, seria dizer "Deus sem nome..." - com a presença de reticências. Esta temática, entre o inominável e os múltiplos nomes de Deus, representa um lugar que é, ao mesmo tempo, filosófico e religioso, onde há crítica do religioso para o filósofo e do filósofo para o religioso. De modo especial, esta temática serve para identificar o modelo do pensamento ricoeuriano, que trata o religioso e o filosófico como áreas independentes, com o risco de uma espécie de esquizofrenia. $\mathrm{O}$ ponto interessante que se dá aqui é a relação de seu posicionamento filosófico perante o religioso com o fato de ele ser professor de filosofia de universidade pública. Assim afirma Ricoeur: "Quero dizer que quando ensino filosofia, particularmente na universidade pública; na universidade laica, falo para todo o mundo e com argumentos acessíveis a todos. E penso que a filosofia argumenta" (RICOEUR, 2002, p. 23).

\section{(2) Um silêncio inquieto}

Já nessa parte da obra, Paul Ricoeur elege a estátua Projeto para um átomo, de Henry Moore, como a imagem do século. Tal estátua está em um lugar simbólico, onde se deu a primeira reação controlada que desembocou na criação da bomba atômica. $O$ silêncio inquieto dá-se no encontro das pessoas que passam por aquele ambiente e se interrogam sobre o significado de tal obra. O silêncio inquieto é o fruto da "[...] multiplicidade das significações" (RICOEUR, 2002, p. 31) de uma obra e aquilo que as pessoas descobrem, destaca Ricoeur, é o que realmente importa, não a intenção do autor. Há um silêncio inquieto quando pensamos em tudo que aconteceu no século $\mathrm{XX}$, ou melhor, com as palavras de Ricoeur, no medonho século $X X$. A grande marca do fim de tal século é a queda do muro de Berlim, mas isto não significa a certeza de um alívio, mas um grande ponto de interrogação. O filósofo francês recorda as marcas trágicas que o século XX deixou na história, como as Grandes Guerras, o totalitarismo. No entanto, há também boas marcas, como as conquistas estudantis na França em 1968 e a revolução sexual. Assim, para o autor, o final deste século traz vários questionamentos, será que as tragédias se repetirão? Será que manteremos nossas conquistas? Será que nosso século, o século XXI, pode ser pior do que aquilo que se passou? 


\section{(3) O poder e a fragilidade}

Neste novo bloco, Paul Ricoeur lembra da figura bíblica de Jonas, que é um profeta mandado por Deus para avisar o povo de Nínive do iminente castigo divino. Segundo Ricoeur, com Jonas aprendemos que “[...] não se deve temer somente o que é provável, mas também o que é possível" (RICOEUR, 2002, p. 46). Ou seja, o grande ponto de interrogação que foi apresentado pelo autor no último bloco, de não saber como será o século XX, deve ser enfrentado com temor, já que várias coisas ruins são possíveis de acontecer. Uma das grandes características da modernidade é a multiplicidade de poderes. No entanto, Ricoeur quer nos alertar que, se multiplicamos o poder, consequentemente, multiplicamos a fragilidade, e onde há fragilidade deve haver responsabilidade.

\section{(4) O filósofo, o poeta e o político}

Na presente parte, Paul Ricoeur apresenta uma reflexão sobre o que seria a obra filosófica. Para isto, ele aponta o quadro Aristóteles contemplando um busto de Homero, de Rembrandt, como símbolo daquilo que ele entende como obra filosófica. Neste ponto, ele discorda do título original do quadro, afirmando: “[...] Aristóteles não contempla o busto de Homero; ele o toca" (RICOEUR, 2002, p. 52). A figura de Aristóteles é a do filósofo como Ricoeur o entende, que toca no poético, mas não se confunde com o poético, assim como não se confunde com o religioso. Há, ainda, no quadro mais uma figura, além do filósofo e do poeta, a do político, que aparece através de uma pequena medalha de Alexandre, que Aristóteles usa, representando que “[...] o político está sempre silenciosamente presente, discretamente presente, no plano de fundo da relação entre poética e filosofia" (RICOEUR, 2002, p. 54). Ora, mais uma coisa chama a atenção de nosso autor, Aristóteles está vestido com roupas contemporâneas, com as roupas não de sua época, mas com as de Rembrandt, significando que a filosofia é sempre contemporânea. Assim, Paul Ricoeur busca definir a obra filosófica por meio da figura do filósofo, que necessita tocar a poesia (esta entendida não apenas por meio do poema, mas por tudo aquilo que é produtor de sentido) para refletir acerca da atualidade, tendo como plano de fundo o político, o qual sempre aparece nos pensamentos filosóficos mascarado pela ética. 


\section{(5) A primeira palavra jamais é a nossa}

Por fim, no quinto e último bloco, Paul Ricoeur recorda que estamos, após a queda do muro de Berlim, que simboliza o fim do século XX, diante de um novo mundo, de um mundo desconhecido e interrogativo. Alguns sinais do novo século já podemos perceber, como uma economia que não é capaz de produzir corretivos para uma retribuição justa. Ora, quem testemunhou as grandes tragédias do século XX pode pensar: "isso não tem como ser pior do que aquilo que vivemos com as guerras, com o totalitarismo!". No entanto, nosso autor quer lembrar que a democracia é "[...] um sistema que só funciona se as pessoas acreditam nele. Pois não repousa sobre a legitimidade ou sobre a força, repousa sobre a confiança" (RICOEUR, 2002, p. 64). Além disso, a maior parte da história da humanidade foi vivida por sistemas não democráticos. Neste sentido, filosofar é temer a possibilidade do que pode acontecer e, ao mesmo tempo, ter esperança, apostar em dias melhores. Tal aposta do filósofo se dá através de sua busca por novos sentidos, que são encontrados na poesia. Por isso, enquanto filósofos, afirmamos: a primeira palavra jamais é a nossa. Sendo assim, encerrando a entrevista, Ricoeur questiona se a história não seria também fonte de esperança, pois se sempre tivemos poetas e filósofos, por que neste novo século isso seria diferente?

À guisa de uma conclusão, podemos dizer que vivemos em tempos, em nosso Brasil, que a democracia é questionada e os testemunhos daqueles que sofreram com o totalitarismo, como as vítimas da ditadura militar, são esquecidos. Diante deste cenário, O único e o singular faz um convite: nós, enquanto filósofos, não podemos esquecer que existe apenas filosofia contemporânea e ela sempre está em relação com o político. Paul Ricoeur nos inspira, ao lembrar dos males vividos e de sua postura diante de diferentes situações, como diante da temática religiosa, ao tratar o filosofar como um compromisso que é, ao mesmo tempo, concreto, temporal e pessoal. Por outro lado, como consequência disso, esta postura também pode ser adotada na leitura de seus livros que, por tratarem de temáticas delimitadas, não articulam com tanta evidência a questão poética, ou a questão política, ou as diferentes questões que surgem de nossa veste contemporânea. Tais elementos, como vimos neste brilhante livro, são essenciais para o filosofar. Por esta reflexão sobre o que seria filosofar, podemos afirmar: $O$ único e o singular deve ser lido e apresentado como uma importante obra para começar a compreender a grandeza e a 
riqueza da obra ricoeuriana, tanto para a filosofia, quanto para nossos dias do presente e do futuro.

\section{Referências bibliográficas}

Ricoeur, Paul. O único e o singular. Tradução: Maria Leonor F. R. Loureiro. São Paulo: Editora UNESP; Belém: Editora da Universidade Estadual do Pará, 2002. 81 p.

Recebido em: 04/03/2020 | Aprovado em: 23/05/2020 